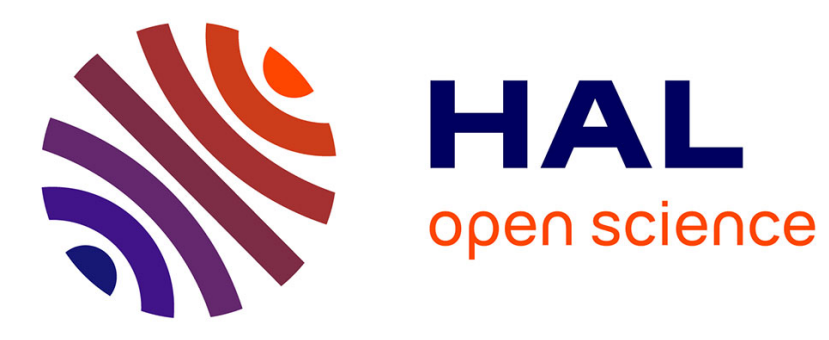

\title{
Toward Generic Models of Hemoproteins
}

Mamadou Lo, Dinesh Mahajan, Jennifer A. Wytko, Corinne Boudon, Jean

Weiss

\section{To cite this version:}

Mamadou Lo, Dinesh Mahajan, Jennifer A. Wytko, Corinne Boudon, Jean Weiss. Toward Generic Models of Hemoproteins. Organic Letters, 2009, 11 (12), pp.2487-2490. 10.1021/ol900774d . hal03379182

\section{HAL Id: hal-03379182 \\ https://hal.science/hal-03379182}

Submitted on 14 Oct 2021

HAL is a multi-disciplinary open access archive for the deposit and dissemination of scientific research documents, whether they are published or not. The documents may come from teaching and research institutions in France or abroad, or from public or private research centers.
L'archive ouverte pluridisciplinaire HAL, est destinée au dépôt et à la diffusion de documents scientifiques de niveau recherche, publiés ou non, émanant des établissements d'enseignement et de recherche français ou étrangers, des laboratoires publics ou privés. 


\title{
Toward Generic Models of Hemoproteins
}

XXXX

Vol. $x x$, No. $x$

\section{Mamadou Lo, ${ }^{\dagger}$ Dinesh Mahajan, ${ }^{\dagger}$ Jennifer A. Wytko, ${ }^{\dagger}$ Corinne Boudon, ${ }^{\ddagger}$ and Jean Weiss ${ }^{\star, \dagger}$}

\author{
Chimie des Ligands à Architecture Contrôlée (CLAC), and Laboratoire \\ d'Electrochimie, Institut de Chimie, UMR 7177 CNRS-Université de Strasbourg, \\ 4 rue Blaise Pascal, 67008 Strasbourg Cedex, France
}

jweiss@chimie.u-strasbg.fr

Received April 9, 2009
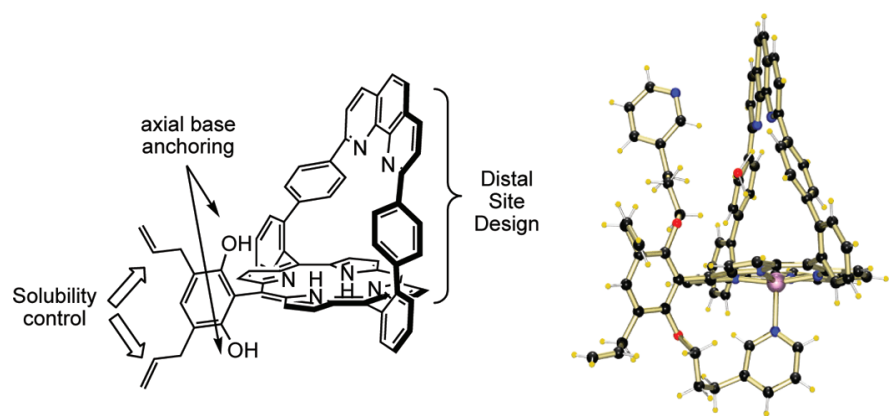

The versatility of a resorcinol-substituted phenanthroline-strapped porphyrin was enhanced by appending allyl chains via a double Claisen rearrangement. Two pyridine arms were then appended to the resorcinol oxygens. This multifunctional porphyrin is a suitable generic building block for the preparation of liposoluble heme protein models. X-ray characterization of the pentacoordinated zinc complex and the binding of a sixth imidazole ligand to the ferric complex both suggest a facilitated access to an empty distal site.

Using a common tetrapyrrolic structure for the incorporation of iron into globins, hemoproteins achieve a variety of functions in living organisms as a result of a highly specific distal environment. ${ }^{1}$ Among these functions, tetraelectronic oxygen reduction by cytochrome $c$ oxidase fuels the production of ATP through a proton gradient generated across the membrane. ${ }^{2}$ The understanding of the sophisticated active center of this enzyme has triggered very elegant synthetic work and produced a large variety of bioinorganic models. ${ }^{2,3}$ Based on the actual knowledge of the cooperative interplay between $\mathrm{Cu}_{\mathrm{B}}$ and $\mathrm{Fe}_{\mathrm{A} 3}$ in the binding of oxygen and the performances of existing models, the development of ac-

† Chimie des Ligands à Architecture Contrôlée.

$\leftarrow$ Laboratoire d'Electrochimie.

(1) Yeung, N.; Lu, Y. Chem. Biodiv. 2008, 5, 1437.

(2) Collman, J. P.; Decréau, R. A. Chem. Commun. 2008, 5065, and references therein.

(3) Chufan, E. E.; Puiu, S. C.; Karlin, K. D. Acc. Chem. Res. 2007, 40, cessible synthetic electrocatalysts for oxygen reduction can be envisioned.

As the result of a long process of building specific distal and proximal sites, the syntheses of hemoprotein models usually orginate from generic building blocks such as a mesotetraaminophenyl porphyrin that is equipped with reactive anchoring points. ${ }^{4}$ In the search for rigid ligands that would facilitate both isolation and characterization of intermediates, we have developed functional mimics of cytochrome $c$ oxidase based on phenanthroline-strapped porphyrins that can be prepared on large scale. ${ }^{5}$ Our initial strategy was extended to a generic building block that can be systematically varied

(4) (a) Collman, J. P.; Boulatov, R.; Sunderland, C. J.; Fu, L. Chem. Rev. 2004, 104, 561. (b) Ruzié, C.; Even-Hernandez, P.; Boitrel, B. Org. Lett. 2008, 10, 2673, and references therein.

(5) (a) Melin, F.; Boudon, B.; Lo, M.; Schenk, K. J.; Bonin, M.; Ochsenbein, P.; Gross, M.; Weiss, J. J. Porphyrins Phthalocyanines 2007, 11, 212. (b) Wytko, J. A.; Graf, E.; Weiss, J. J. Org. Chem. 1992, 57, 1015 . 
to assess small effects of ancillary ligands in enzyme models. The efficient synthesis of a generic framework $\mathbf{3}$ comprising a phenanthroline (phen)-strapped porphyrin is described. The porphyrin bears anchoring points for both pendant proximal and distal bases and for side chains to control solubility or for subsequent incorporation of the models into membranes and polymers. ${ }^{6}$

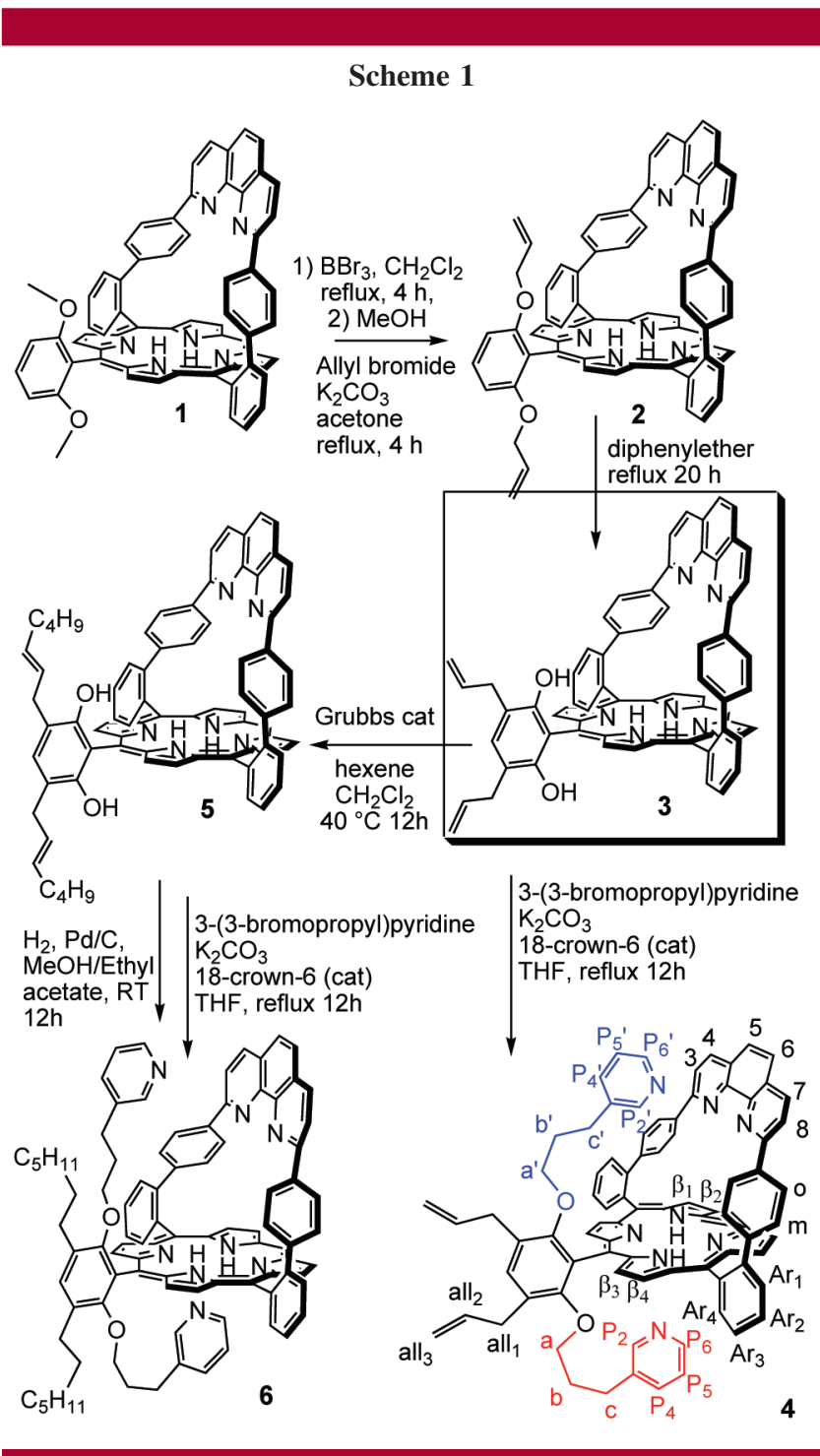

The synthesis of the phen-strapped porphyrin $\mathbf{1}$ bearing a dimethoxyresorcinol substituent anchored to one meso position was performed according to previously reported methods. ${ }^{5 a}$ Porphyrin 1 can be prepared from a meso-bromo species ${ }^{7}$ that is readily available on the scale of a few grams. This availability fulfills an important requirement for the design of a generic heme model. Initial development of cytochrome $c$ oxidase models performed on $\mathbf{1}$ was hindered by major solubility problems; therefore, additional functional groups were introduced on the framework. The dimethoxy derivative 1 was cleaved with boron tribromide and then alkylated with allyl bromide in the presence of potassium carbonate in acetone. The diallyl derivative $\mathbf{2}$, obtained in $79 \%$ yield, was subjected to the harsh conditions of Claisen rearrangement in degassed, refluxing diphenyl ether. After the double rearrangement, the dihydroxylated resorcinol analogue 3, obtained in $60-85 \%$ yield, displayed significantly enhanced solubility compared to that of the original resorcinol derivative $\mathbf{1}$.

This generic framework 3 now possesses two anchoring points (hydroxy groups) for built-in axial bases, as well as reactive peripheral allyl chains for further control of the lipophilicity. To demonstrate both possibilities, the dihydroxyl derivative 3 was reacted with 3-(3-bromopropyl)pyridine or its mesylate analogue to afford the bis-pyridine appended porphyrin 4 in 58\% yield. Alternatively, reaction of $\mathbf{3}$ with 1-hexene under Grubbs conditions for metathesis ${ }^{8}$ afforded the bis-olefinic derivative $\mathbf{5}$ in $83 \%$ yield. Reduction of 5 to the corresponding saturated intermediate and subsequent alkylation with pyridine side arms led to $\mathbf{6}$, an analog to 4 bearing two peripheral $\mathrm{C}_{7}$ chains, in $65 \%$ yield. ${ }^{1} \mathrm{H}$ NMR spectra of both 4 (Figure 1) and 6 (Supporting Information)

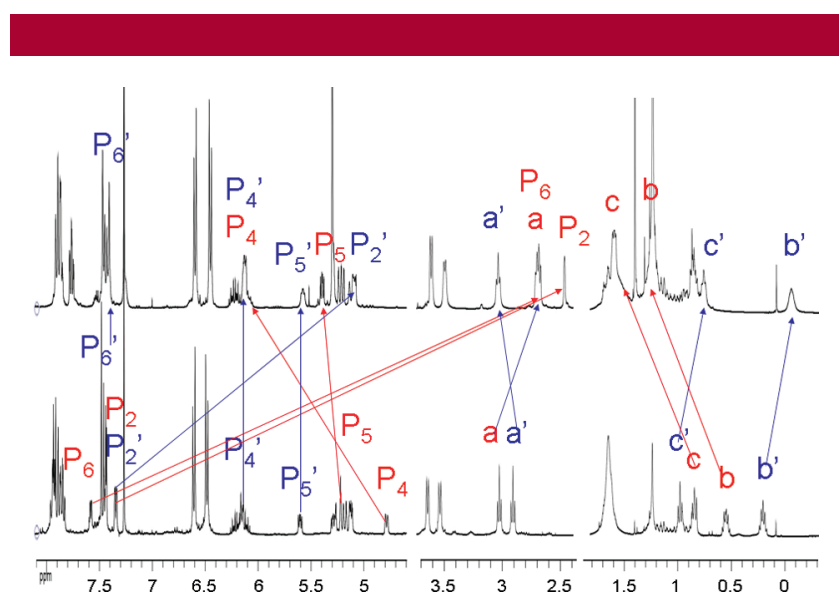

Figure 1. Significant chemical shift displacements observed in $\mathbf{4 Z n}$ (top trace) upon zinc complexation in $\mathbf{4}$ (bottom trace) $\left({ }^{1} \mathrm{H}\right.$ NMR, $400 \mathrm{MHz}, \mathrm{CDCl}_{3}$ ). Detailed assignment is given in Supporting Information, and proton numbering is in Scheme 1. Protons of the proximal pendant chain are red, and those of the distal pendant chain are blue.

showed the proximity of both pendant arms above and below the porphyrin nucleus, as indicated by the shielding of $\mathrm{H}_{\mathrm{c}}$ (0.18 ppm) and $\mathrm{H}_{\mathrm{c}^{\prime}}(0.55 \mathrm{ppm})$.

To demonstrate the usefulness and versatility of this generic building block, zinc(II) and ferric complexes were prepared. On the basis of previous observations with imidazole side arms ${ }^{5 \mathrm{a}, 9}$ it was expected that only pentacoordinated metal complexes would be observed in the presence of two pyridine side arms. For the zinc complex, ${ }^{1} \mathrm{H}$ NMR spectral changes confirmed both the pentacoordinated nature of the complex and the exclusive coordination of the proximal pyridine. The effects of the zinc binding on the NMR spectra are summarized in Figure 1 for $\mathbf{4}$ and $\mathbf{4 Z n}$. Proton assignments of the free ligands $\mathbf{4}$ and $\mathbf{6}$ and their zinc complexes $4 \mathrm{Zn}$ and $\mathbf{6 Z n}$ are based on COSY/ROESY experiments (see Supporting Information). The strong shielding of the protons $\alpha$ to the nitrogen on both pyridines suggested that both side arms interact with the central metal 
core. However, careful examination of related signals on the propyl linkers confirmed that the proximal side arm was the only one for which a deshielding effect was observed for $\mathrm{H}_{\mathrm{b}}$ and $\mathrm{H}_{\mathrm{c}}$, while $\mathrm{H}_{\mathrm{a}^{\prime}}$ is simultaneously pulled out of the shielding area. These displacements result from the bending of the resorcinol moiety toward the open face of the porphyrin due to the constraints generated by ligation of the proximal pyridine and the positioning of $\mathrm{H}_{b}$ and $\mathrm{H}_{\mathrm{c}}$ away from the porphyrin plane. The shielding of $\mathrm{H}_{\mathrm{P} 2^{\prime}}$ and remains puzzling and was assigned to an interaction of the distal pyridine with the distal pocket. A speculative interpretation is that the shielding of this specific distal proton is due to ring current of either the side phenyls of the strap or the phen or both. Reasons for the location of $\mathrm{H}_{\mathrm{P} 2^{\prime}}$ and in this area of space include (1) the possible formation of a hydrogen bond with a water molecule in the phen binding site or (2) simple $\pi$-stacking interactions within the pocket. Either reason is plausible, but neither could be established unequivocally.

X-ray diffraction confirmed the postulated coordination geometry of the zinc(II) complex. Single crystals of the zinc complex were obtained by slow diffusion of heptane into a chloroform solution of $\mathbf{4 Z n}$, followed by slow evaporation. The crystal structure is depicted in Figure $2 .{ }^{10}$ The zinc atom

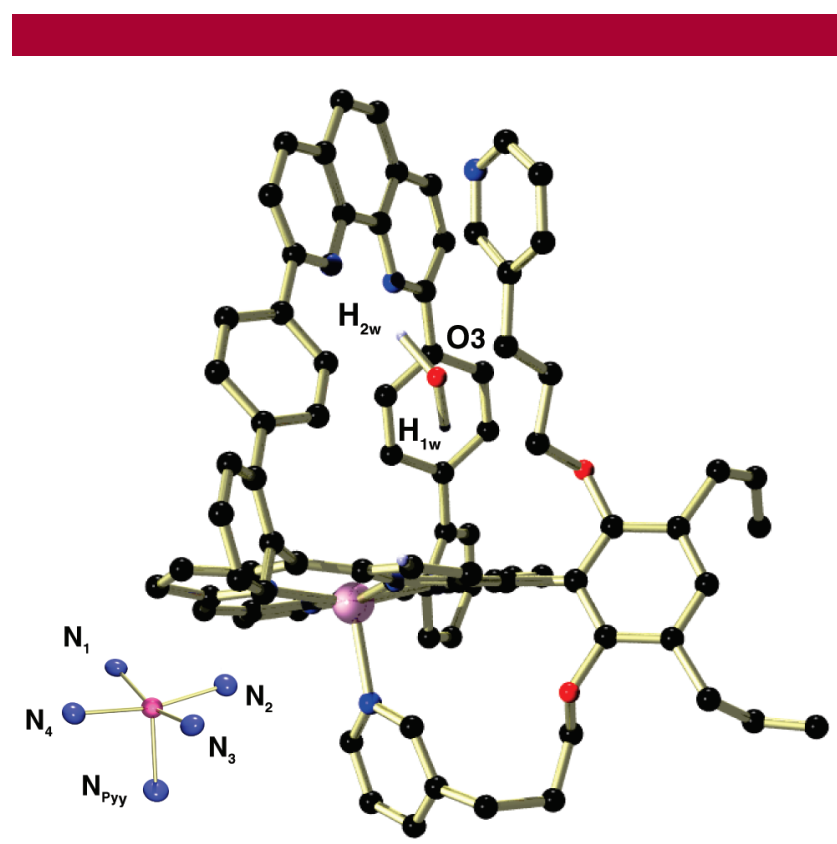

Figure 2. Solid-state structure of $\mathbf{4 Z n}$. Solvent molecules $\left(\mathrm{CHCl}_{3}\right)$ omitted for clarity. ${ }^{10}$ The inset provides the atom numbering used in Table 1 for the analysis of $\mathrm{Zn}$ coordination geometry.

is pentacoordinated in a ruffled porphyrin core. Table 1 summarizes the zinc-nitrogen distances. The square base pyramidal coordination around the zinc is significantly distorted, and the zinc-pyridine bond leans toward the resorcinol side of the ligand. The zinc is out of plane by $0.29 \AA$ from a N4 centroid with a $\mathrm{Zn}-\mathrm{N}_{\mathrm{Py}}$ distance of $2.17(1)$ $\AA$, which is in the range of previously reported pentacoordinated zinc(II) porphyrins. ${ }^{11}$ The phen pocket is empty in the close proximity of the porphyrin. The phen binding site
Table 1. Distances and Angles Representative of Distorted Zinc Coordination in $\mathbf{4 Z n}$

\begin{tabular}{cccc}
\hline $\mathrm{N}_{i}$ & $\begin{array}{c}\mathrm{N}_{i}-\mathrm{Zn} \\
\text { distance }\end{array}$ & $\begin{array}{c}\mathrm{N}_{i}-\mathrm{Zn}-\mathrm{N}_{j} \\
\text { angle (deg) }\end{array}$ & $\begin{array}{c}\mathrm{N}_{i}-\mathrm{Zn}-\mathrm{N}_{\mathrm{Py}} \\
\text { angle (deg) }\end{array}$ \\
\hline $\mathrm{N}_{1}-\mathrm{Zn}$ & 2.045 & $\mathrm{~N}_{1} \mathrm{~N}_{2} 89.12$ & 105.73 \\
$\mathrm{~N}_{4}-\mathrm{Zn}$ & 2.074 & $\mathrm{~N}_{4} \mathrm{~N}_{1} 88.92$ & 97.29 \\
$\mathrm{~N}_{3}-\mathrm{Zn}$ & 2.052 & $\mathrm{~N}_{3} \mathrm{~N}_{4} 88.05$ & 94.14 \\
$\mathrm{~N}_{2}-\mathrm{Zn}$ & 2.073 & $\mathrm{~N}_{2} \mathrm{~N}_{3} 89.29$ & 96.04 \\
\hline
\end{tabular}

is occupied by a water molecule that is $\mathrm{H}$-bonded to the phen's nitrogen atoms. The presence of a solvent molecule in the phen pocket was observed in two previous cases. ${ }^{12,13}$ In the structure depicted in Figure 2, this solvate is maintained by one stronger $\left(d\left(\mathrm{~N}_{8}-\mathrm{H}_{2 \mathrm{w}}\right)=1.87(1) \AA\right)$ and one weaker $\left(d\left(\mathrm{~N}_{7}-\mathrm{H}_{2 \mathrm{w}}\right)=2.34(3) \AA\right)$ hydrogen bond that weaken the $\mathrm{H}_{2 \mathrm{w}}-\mathrm{O}_{3}$ bond $(d=1.21(6) \AA)$ versus the $\mathrm{H}_{1 \mathrm{w}}-\mathrm{O}_{3}$ bond $(d=1.18(6) \AA)$. Globally, the solid-state positioning of the distal pyridine accounts quite well for the shielded NMR resonance of $\mathrm{H}_{\mathrm{P}^{\prime}}$ and resulting from the phen's ring current.

The potential use of $\mathbf{4 F} \mathrm{e}^{\mathrm{III}}$ as models of hemoprotein and cytochrome $c$ oxidase is conditioned by the reproduction of the coordination scheme of $\mathbf{4 Z n}$ with iron(III) and eventually with iron(II). The ferric complex was prepared quantitatively by metalation with $\mathrm{FeCl}_{2}$ in THF. The zinc coordination geometry is believed to mimic the pentacoordination of the ferric complex. Based on the length of the propyl linker between the pyridine and the resorcinol platform, only one of the pyridines should be able to bind iron(III). In that case, the ferric complex presents a distal site that remains available for the coordination of small exogenic ligands and should display peculiar behavior upon addition of a sixth ligand like imidazole. This assumption was preliminarily confirmed by UV-vis spectroscopy and electrochemistry.

The evolution of both the phen's absorption bands and the iron(III) porphyrin's Q-bands in [4Fe $\left.\mathbf{F e}^{\mathrm{III}}\right] \mathbf{C l}$ upon addition of $0-1$ equiv of imidazole is depicted in Figure 3. No further

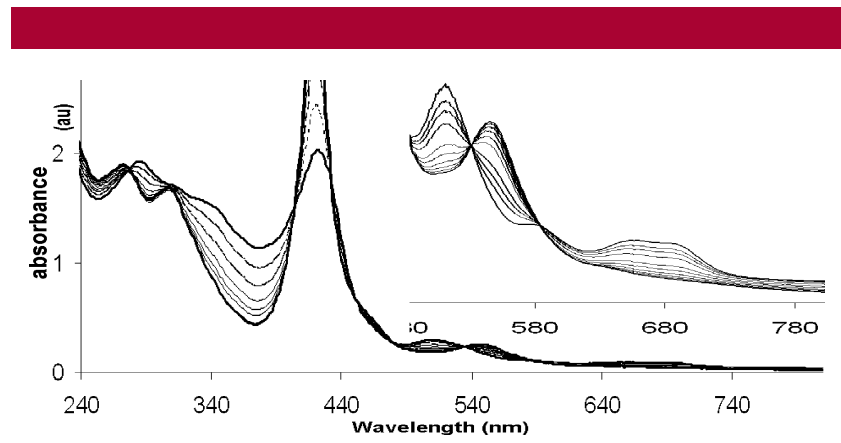

Figure 3. Spectrophotometric titration of $\mathbf{4 F e}\left(6.1 \times 10^{-4} \mathrm{M}\right)$ with $0-1.1$ equiv of imidazole $\left(1.2 \times 10^{-2} \mathrm{M}\right)$ in $\mathrm{CH}_{2} \mathrm{Cl}_{2}$ at $297 \mathrm{~K}$.

evolution was observed at higher imidazole/[4Fe] ratios. On the basis of previous observations for zinc(II) complexes, these spectral changes clearly indicate that imidazole binding 
in the distal pocket is highly favored by the formation of a hydrogen bond with the nitrogen atoms of the phen moiety. The association constant of imidazole with $\left[\mathbf{4 F} \mathrm{F}^{\mathrm{III}}\right] \mathbf{C l}$ could not be estimated on the basis of titration experiments because the initial coordination state of $\left[\mathbf{4 F} \mathrm{e}^{\mathrm{III}}\right]$ was unknown, as chloride may be partially bound to it, preventing fine data analysis.

Further evidence for the binding of imidazole at the distal site was obtained from cyclic voltammetry (Figure 4). In

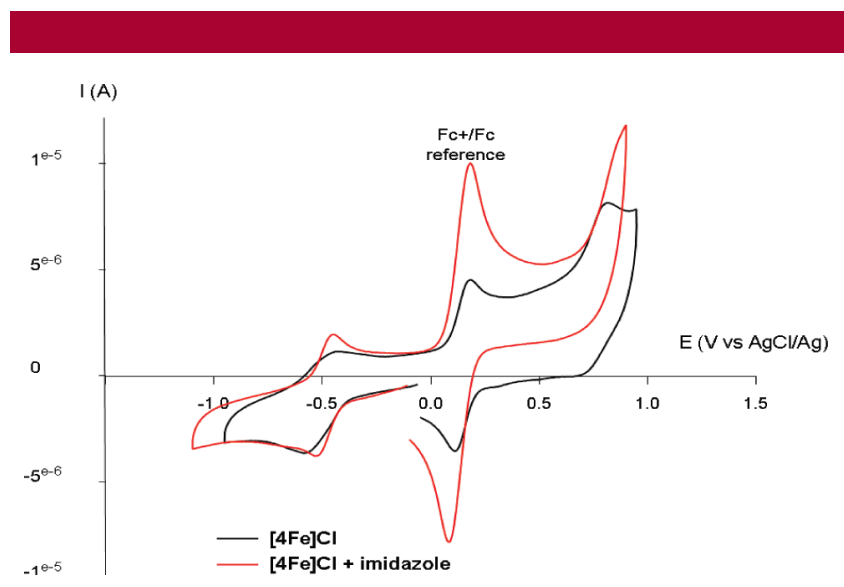

Figure 4. Cyclic voltammetry behavior of $\left[4 \mathrm{Fe}^{\mathrm{III}}\right] \mathrm{Cl}\left(5 \times 10^{-4}\right.$ $\mathrm{M})$ in $\mathrm{CH}_{2} \mathrm{Cl}_{2}+0.1 \mathrm{M} \mathrm{TBAPF}_{6}$ (black trace) and after addition of imidazole (1 equiv). Working electrode: Pt disk, counter electrode $\mathrm{Pt}$ wire, reference $\mathrm{AgCl} / \mathrm{Ag}$, with $\mathrm{Fe}(\mathrm{Cp})_{2}$ calibration. $V=0.1 \mathrm{~V} / \mathrm{s}$.

the absence of imidazole, the reduction of $\left[4 \mathrm{Fe}^{\mathrm{III}}\right] \mathrm{Cl}$ or $\left[\mathbf{4 F e} \mathbf{e}^{\mathrm{II}}\right] \mathbf{P F}_{\mathbf{6}}$ (provided in Supporting Information) into the ferrous species was poorly defined, as expected for a coordinatively deficient iron(III/II) redox couple. The poor definition of the redox couple is representative of ill-defined coordination (partially coordinated $\mathrm{Cl}$ ). In particular, the lack of reversibility in the anodic return peak may be due to interference of residual water (from the solvent) on the iron(II) center after reduction. In the presence of imidazole, electrochemical reversibility was reached as a result of the binding of imidazole in both the ferric and the ferrous states. A better definition of the signal corresponds to an unchanged coordination geometry in both redox states. This suggests that the distal pyridine does not interact with the Fe(II) state. The zinc complex thus mimics the pentacoordinate states of both $\mathrm{Fe}(\mathrm{III})$ and $\mathrm{Fe}(\mathrm{II})$.

In conculsion, in its reduced state $\mathbf{4 F e}$ possesses an empty cavity that is suitable for exogenic ligands. The solubility of this model can be adjusted, as demonstrated by the attachment of alkyl side chains, and anchoring groups for further incorporation into artificial membranes are present. In addition, this candidate for a cytochrome $c$ oxidase model was obtained from a generic building block that possesses a distal site, which is predefined by the phen strap, and two hydroxyl groups for the attachment of axial bases and ancillary ligands. The binding of copper(I) within the phen moiety and the electrocatalytic behavior of the iron(III) and iron(II) complexes are currently being investigated.

Acknowledgment. This work was supported by the CHEMBLAST (Conception of HEmoprotein Models for Biomimetic Large scale Applications and mechanistic STudies) program of the National Research Agency. M.L. and D.M. are grateful to the Ministry of Education and Research for Ph.D. and postdoctoral fellowhips.

Supporting Information Available: Synthetic experimental descriptions, NMR assignments, and X-ray and electrochemical details. This material is available free of charge via the Internet at http://pubs.acs.org.

OL900774D

(6) (a) Collman, J. P.; Boulatov, R. Angew. Chem., Int. Ed. 2002, 41, 3487. (b) Ferrand, Y; Le Maux, P.; Simonneaux, G. Tetrahedron: Asymmetry $\mathbf{2 0 0 5}, 16,3829$.

(7) Koepf, M.; Wytko, J. A.; Bucher, J.-P.; Weiss, J. J. Am. Chem. Soc. 2008, 130, 9994.

(8) (a) Liu, X.; Sternberg, E.; Dolphin, D. Chem. Commun. 2004, 57, 852. (b) Liu, X.; Sternberg, E.; Dolphin, D. J. Org. Chem. 2008, 73, 6542. (c) Langford, S. J.; Latter, M. J.; Woodward, C. P. Org. Lett. 2006, 8, 2595. (9) Melin, F.; Choua, S.; Bernard, M.; Turek, P.; Weiss, J. Inorg. Chem. 2006, 45,10750 .

(10) Crystallographic details are available in Supporting Information. The structure has been deposited with the CCDC under number CCDC 724160 .

(11) Cheng, B.; Scheidt, W. R. Inorg. Chim. Acta 1995, 237, 5.

(12) Ochsenbein, P.; Bonin, M.; Schenk, K.; Froidevaux, J.; Wytko, J; Graf, E.; Weiss, J. Eur. J. Inorg. Chem. 1999, 2, 1175.

(13) Paul, D.; Melin, F.; Hirtz, C.; Wytko, J.; Ochsenbein, P.; Bonin, M.; Schenk, K.; Maltese, P.; Weiss, J. Inorg. Chem. 2003, 42, 3779. 